\title{
TENSILE PROPERTIES OF RUBBER COMPOUNDS AT HICH RATES OF STRETCH
}

\author{
By Frank L. Roth and William L. Holt
}

\begin{abstract}
With the aim of determining whether the tensile properties of a rubber compound measured at high stretching rates offer any better indication of resistance to abrasive wear than the properties measured at the usual testing rates, a special apparatus was developed for stretching ring specimens to rupture by means of a falling weight. Tensile properties of the ring specimens were determined from a study of the position of the weight as a function of time. The position of the weight was recorded at equal time intervals on a paper tape, one end of which was fixed to the weight. The tape was pulled through a spark gap as the weight fell. The timing of the sparks was controlled by a tuning fork. Specimens were stretched to the point of rupture in about one-half to three quarters of a second. The work of extension was determined as a function of the elongation of the specimen from the instantaneous positions and corresponding speeds of the weight. Stress-strain relationships were then obtained from the work of extension.

Tests were made on a range of cures of each of four rubber compounds. One of these was a pure gum compound, and each of the other three contained 25 volumes of a filler per 100 volumes of crude rubber. The three fillers used were channel black, soft black, and clay.

A comparison of these data with similar data for a rate of stretch which lies in the range of speeds common to the usual routine tests fails to show that the tensile properties measured at the high stretching rates offer any better indication of resistance to abrasive wear than the properties measured at the usual testing rates.
\end{abstract}

\section{CONTENTS}

Page

I. Introduction

II. Rubber compounds investigated

III. Apparatus and procedure...

1. Rapid stretching

(a) Description of apparatus..... 606

(b) Sample calculation

(c) Precision

2. Slow stretching

IV. Experimental results

1. Stress-strain relationships_... 613

2. Work of extension

V. Summary and conclusions

\section{INTRODUCTION}

It has been suggested by several authors that some relationship may exist between the stress-strain properties of a rubber compound and its resistance to abrasive wear. Wiegand ${ }^{1}$ pointed out in 1920 that since

' W. B. Wiegand, Some aspects of the rubber stress-strain curve, Can. Chem. J. 4, 160 (1920). 
the wear of a tire tread consists in the gouging or tearing out of small masses of rubber, the resistance to abrasive wear might depend on the amount of work performed in stretching the rubber to rupture. A chart accompanying this suggestion showed that for a compound containing 25 volumes of channel black per 100 volumes of rubber this work was greater than for compounds containing other fillers or other proportions of channel black. It is well known that compounds containing from 25 to 35 volumes of channel black have the highest resistance to abrasive wear. Grieder ${ }^{2}$ found no exact proportionality between the work of extension and abrasive resistance obtained in the laboratory, but compounds which showed high resistance to abrasion also showed relatively large work of extension. In a more recent investigation on the reinforcement of rubber with carbon black, Wiegand ${ }^{3}$ states that the resistance of a rubber compound to abrasive wear is undoubtedly influenced not only by the work of extension to rupture but also by the work of extension to intermediate elongations.

Principally because of experimental difficulties in obtaining simultaneous values of extension and force at high rates of stretch, most of the previous investigations have been limited to relatively slow rates. However, it has long been known that the tensile properties of a vulcanized rubber compound depend on the rate at which the specimens are stretched. In 1903 Bouasse and Carrière ${ }^{4}$ noted that for a rubbersulfur compound the extension of a specimen for a given load was greater when the load was applied slowly than when it was applied quickly. The extensions were carried out to about 600 percent of the unstretched length of the specimens at rates ranging from 0.5 to 7 percent per second. 5 Somerville, Ball and Edland 6 noted for a more modern pure-gum compound a similar effect of stretching rates from 0.3 to 3 percent per second and for extensions to 350 percent.

Holt, ${ }^{7}$ using an autographic machine, stretched a tire-tread compound to an elongation of 450 percent at average rates ranging from 10 to 1,500 percent per second. His results also show that for any given strain the stress increases with increasing rate of stretch. Similar results were obtained by Dart and Guth, ${ }^{8}$ who used a method involving photographic recording and employed rates ranging from 2 to 300 percent per second.

The effects of average rates of extension from about 2 to 20 percent per second on the tensile strengths and ultimate elongations for four compounds were reported by the National Bureau of Standards ${ }^{9}$ in 1915. The study showed slightly higher tensile strengths and ultimate elongations for the higher rates of stretch.

The above-mentioned investigators have found small increases in the stress for a given strain, but no one of them has reported any marked advantage in making tests at the higher rates of stretch.

\footnotetext{
${ }^{2} \mathrm{H}$. W. Grieder, The resilient energy and abrasion resistance of vulcanized rubber, Ind. Eng. Chem. 15, 504 $(1923)$.

${ }_{3}$ W. B. Wiegand, The carbon reinforcement of rubber, Can. Chem. and Met. 21, 35 (1937).

${ }^{4} \mathrm{H}$. Bouasse and Z. Carrière, Sur les courbes de traction du caoutchouc vulcanisé, Ann. Faculté Sciences Toulouse, 5 (2), 257 (1903)

5 The rate of stretch for the usual dumbbell specimens ranges from 5 to 25 percent per second for a jaw separation of 20 inches per minute.

${ }^{6}$ A. A. Somerville, J. M. Ball, and L.A. Edland, Autographic stress-strain curves of rubber at low elongations, Ind. Eng. Chem., Anal. Ed. 2, 289 (1930); Reprinted in Rubber Chem. Tech. 3, 689 (1930).

7 W. T. Holt, Behavior of rubber under repeated stresses, Ind. Eng. Chem. 24, 1471 (1931); Reprinted in Rubber Chem. Tech. 5, 79 (1932).

${ }_{8}$ F. E. Dart and E. Guth, The dependency of the stress-strain relationship for rubber upon the rates of stretching, Phys. Rev. 55, 1141 (A) (1939).

' Cir. BS C38 [ed. 3], 60 (1915).
} 
Beadle and Stevens ${ }^{10}$ suggested the use of the impact pendulum for stretching rubber test specimens in order that the tests be made to approach more nearly the sudden stresses experienced by a tire on the road. Later studies by investigators ${ }^{11}{ }^{12}$ using the impact pendulum to determine the work done in stretching rubber to rupture report that high rates of stretch are advantageous in determining the best cure. Stress-strain curves obtained for elongations up to 350 percent at a rate of about 8,000 percent per second by means of a modified impact pendulum ${ }^{13}$ show stresses which are relatively large compared with those obtained by the usual methods of testing.

In a recent investigation of isothermal and adiabatic stress-strain curves for pure-gum compounds, Hauk and Neumann ${ }^{14}$ found that for compounds containing 1 and 2 percent of sulfur "the curves first separate, then at higher elongations approach each other, and finally intersect." In this work the isothermal curves were determined by loading similar strip-specimens with various weights and observing the change in distance between gage marks. The adiabatic curves were determined by applying the stretching force through a calibrated spring and obtaining a cinematographic record of the relative positions of gage marks on both the specimen and the spring. The stretching process for the adiabatic curves was accomplished in less than a second. The same authors, ${ }^{15}$ working with elongations up to about 450 percent, found in another investigation that for various rates of stretch ranging from 50 to 700 percent per second the stress increased with increasing rates.

The purpose of the present investigation was to determine whether the tensile properties measured at high stretching rates offer any better indication of resistance to abrasive wear than the properties measured at the usual testing rates. In this study stress-strain relationships were determined for different types of rubber compounds when stretched rapidly to rupture. The specimens were stretched to rupture in less than a second, so that the tests were nearly adiabatic. The cross sections of the specimens were small compared to their lengths so that the stresses might approach simple tensions in character. In order to make the results for high rates of stretch comparable to those for low rates, similar specimens were used throughout the study.

\section{RUBBER COMPOUNDS INVESTIGATEDI}

Tests were made on a series of specimens of each of four rubber compounds, the compositions and cures of which are shown in table 1. The first compound is referred to as pure gum, that is, it contains no filler. The compounds containing fillers, referred to as loaded compounds and designated by their respective fillers, have a base stock which is as nearly like the pure-gum compound as is practicable.

$10 \mathrm{C}$. Beadle and H. P. Stevens, Impact tensile tests on rubber and a comparison with tensile and hysteresis tests, Proc. Int. Rubber Cong. (London) 4, 344 (1911).

${ }^{11}$ A. van Rossem and H. B. Beaverdam, Tensile tests of vulcanized rubber at high speed, Rev. gén. caoutchouc 7, 27 (1930); Reprinted in Rubber Chem. Tech. 4, 147 (1931)

${ }^{12} \mathrm{G}$. W. Albertoni, Impact machine for rubber testing, Ind. Eng. Chem. 9, 30 (1937); Reprinted in Rubber Chem. Tech. 10, 317 (1937).

${ }_{13} \mathrm{G}$. W. Albertoni, Impact machine for rubber testing, Ind. Eng. Chem. 9, 30 (1937); Reprinted in Rubber Chem. Tech. 10, 317 (1937).

14 V. Hauk and W. Neumann, Isothermal and adiabatic stress-strain curves of tulcanized rubber, Monatsh. 72, 22 (1938); Translated in Rubber Chem. Tech. 12, 64 (1939).

is $\mathrm{V}$. Hauk and $\mathrm{W}$. Neumann, A time effect in the rapid elongation of rubber, Naturwissenschaften $26,36$. and 461 (1938); Translated in Rubber Chem. 'Tech. 12, 518 (1939). 
Each compound contains 25 volumes of filler per 100 volumes of crude rubber.

TABLE 1.-Composition and cure of rubber compounds

\begin{tabular}{|c|c|c|c|c|}
\hline Rubber compounds & $\begin{array}{l}\text { Pure- } \\
\text { gum }\end{array}$ & $\begin{array}{c}\text { Channel- } \\
\text { black }\end{array}$ & $\begin{array}{l}\text { Soft. } \\
\text { black }\end{array}$ & Clay \\
\hline Ingredients & \multicolumn{4}{|c|}{ Parts by weight } \\
\hline $\begin{array}{l}\text { Rubber (smoked sheets) } \\
\text { Sulfur } \\
\text { Zinc oxide } \\
\text { Stearic acid } \\
\text { Benzothiazyl disulfide (Altax) }\end{array}$ & $\begin{array}{r}100 \\
3 \\
5 \\
1 \\
1.0\end{array}$ & $\begin{array}{r}100 \\
3 \\
5 \\
2 \\
1.0\end{array}$ & $\begin{array}{r}100 \\
3 \\
5 \\
2 \\
1.0\end{array}$ & $\begin{array}{l}100 \\
3 \\
5 \\
2 \\
1.0\end{array}$ \\
\hline $\begin{array}{l}\text { Tetramethylthiuram disulfide (Tuads) } \\
\text { Phenyl-beta-naphthylamine } \\
\text { Channel-black (Micronex) } \\
\text { Soft-carbon (P-33) } \\
\text { Clay (Dixie) }\end{array}$ & 1. 5 & $\begin{array}{r}0.1 \\
1.5 \\
49.0 \\
\end{array}$ & $\begin{array}{r}0.1 \\
1.5 \\
49.0 \\
\end{array}$ & $\begin{array}{l}0.1 \\
1.5\end{array}$ \\
\hline $\begin{array}{l}\text { Curing temperature }\left({ }^{\circ} \mathrm{C}\right) \\
\text { Curing times }(\mathrm{min})\end{array}$ & $\left\{\begin{array}{r}142 \\
20 \\
25 \\
\mathrm{x} 30 \\
40 \\
60 \\
75\end{array}\right.$ & $\begin{array}{r}127 \\
20 \\
25 \\
\times 35 \\
50 \\
75\end{array}$ & $\begin{array}{r}127 \\
10 \\
\text { × } 15 \\
20 \\
25 \\
35\end{array}$ & $\begin{array}{r}127 \\
20 \\
25 \\
\times 35 \\
50 \\
75\end{array}$ \\
\hline
\end{tabular}

- Cures selected as optimum for comparisons in the present investigation.

In the selection of the compounds to be studied, the aim was to pick a few simple compounds containing commonly used fillers and differing considerably in tensile and abrasive properties. The addition of channel black to a base stock produces a compound which possesses the greatest resistance to abrasive wear, and which is universally used for tire treads. The compound is stiff and has markedly higher tensile strength than the base stock. When clay is added to the base stock, a stiff compound with relatively low tensile strength and ultimate elongation results. Soft black, however, has little stiffening action, and a soft-black compound has a relatively high nltimate elongation. Such a compound has a tensile strength lese than that of the channel-black compound but more than that of the clay compound.

\section{APPARATUS AND PROCEDURE}

The tensile properties for high rates of stretch were determined by means of a special apparatus in which ring specimens were stretched by means of a falling weight. Slow stretching rates were obtained by use of a modified form of this apparatus and by a Scott tensile machine.

\section{RAPID STRETCHING}

\section{(a) DESCRIPTION OF APPARATUS}

A schematic diagram of the apparatus employed in obtaining stressstrain relationships for high rates of elongation is shown in figure 1. Ring specimens are stretched to rupture by a falling weight, and their stress-strain relationships are determined from a study of the position of the weight as a function of time. The position of the weight is recorded at equal time intervals on a paper tape, one end of which is fixed to the weight. The tape is pulled through a spark 
gap as the weight falls. The timing of the sparks is controlled by a tuning fork which operates the breaker points in the primary circuit of an induction coil. The frequency of the tuning fork is 55.6 vibrations per second, and the time required to stretch a specimen to the

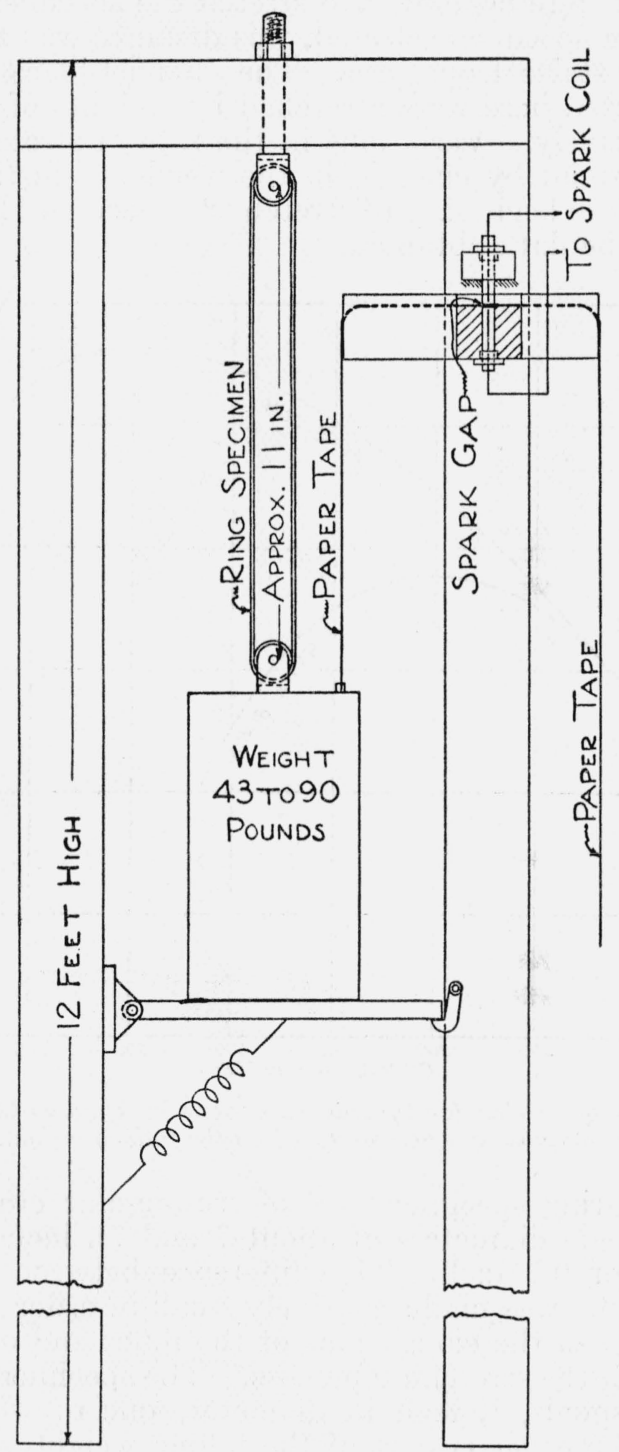

FIGURE 1.-Schematic diagram of the apparatus for determining the tensile properties of rubber by the use of a falling weight.

point of rupture ranges from about one-half to three-quarters of a second. The time involved in stretching the specimen is short enough so that the test may be considered nearly adiabatic. The rate of stretch is not constant, but the average is in the order of 1,000 percent per second. The maximum speeds range from 1,600 to 1,950 percent per second for the pure-gum compounds and from 950 to 
1,500 percent per second for the loaded compounds. The actual rates of stretch for a pure-gum and a loaded compound are shown in figure 2. The fact that the speed for the channel-black specimen selected for this figure does not start from zero indicates that the weight fell some distance before beginning to stretch the specimen. In the case of the pure-gum specimen selected, this distance was zero, and therefore the speed starts from zero. The channel-black and pure-gum specimens selected here were stretched by weights of 90.2 and 42.93 pounds, respectively. Variations in the rate of stretch of the specimen, brought about by changes in the weight or in the distance the weight falls before beginning to stretch the specimen, have no observable effect on the data obtained.

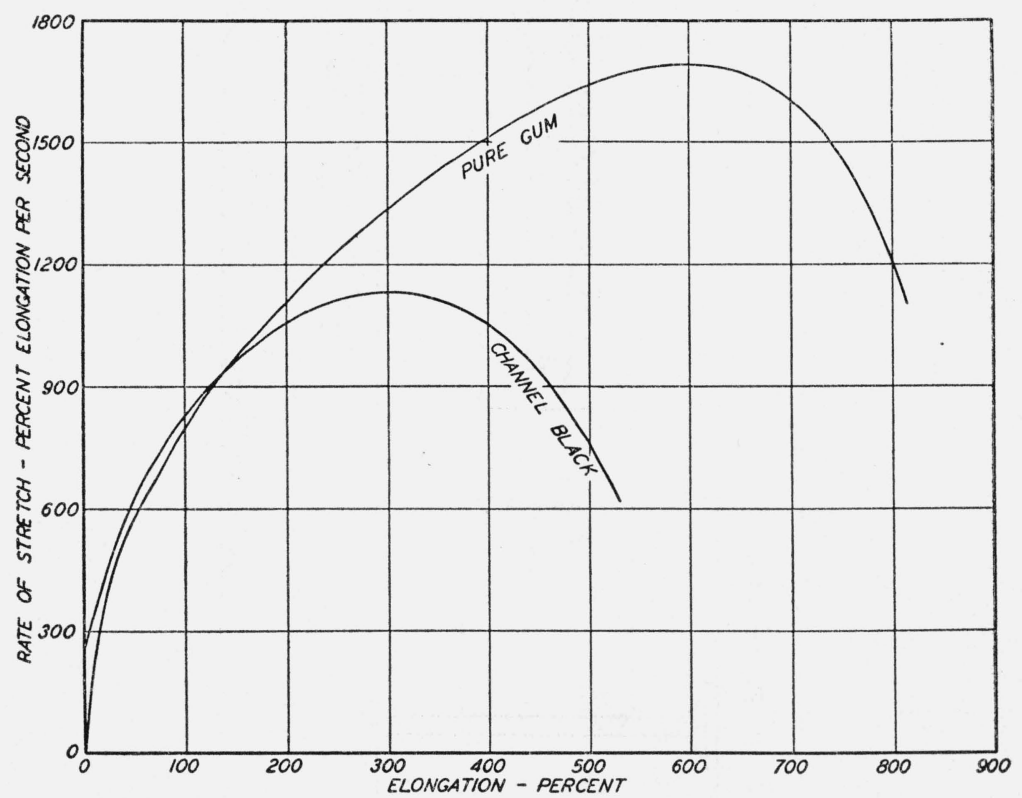

FIGURE 2.-Rates of stretch for typical specimens of channel-black and pure-gum compounds when stretched by the falling weight.

The molded-ring specimens are of rectangular cross section with inside and outside diameters of about 7 and $7 \frac{1}{4}$ inches, respectively, and a width of 0.2 inch. The difference between the inside and outside diameters was made relatively small in order to minimize the difference between the elongations of the inner and outer surfaces of the rings during the stretching process. The specimens are supported on two steel spools, $7 / 8$ inch in diameter, one of which is fixed in position and the other is part of the falling weight. The spools are free to rotate on their axes, and the areas of contact between the ring and the spools are lubricated with castor oil. Except for the highly cured pure-gum compounds, few specimens rupture in or very near the region of contact of the rings with the spools.

The weight is made in several sections so that it can be varied between 43 and 90 pounds by steps of approximately 12 pounds. The upper, or fixed, spool may be raised or lowered to allow the 
weight to fall any desired distance (usually from 0 to 2 inches) before beginning to stretch the specimen.

The spark electrodes consist of tungsten wires inside glass capillary tubes. 'The bore of these tubes is about $0.020 \mathrm{inch}$, and the electrode ends of the wires reach to within about 0.010 inch of the ends of the tubes. The recording tape slides between the tubes, and the tubes are kept in contact with it by the weight of the upper electrode assembly. Strips of adding-machine paper, $1 \frac{1}{4}$ inches wide and 10 feet long, are used for the recording tape. A flat spring keeps the tape taut as the weight falls. The friction of the tape produces no appreciable effect on the motion of the weight since, if the weight is allowed to fall without a specimen in place, its acceleration is found to be equal, within an experimental error of about 1 part in 300 , to the accepted value of $g$, the acceleration of a freely falling body.

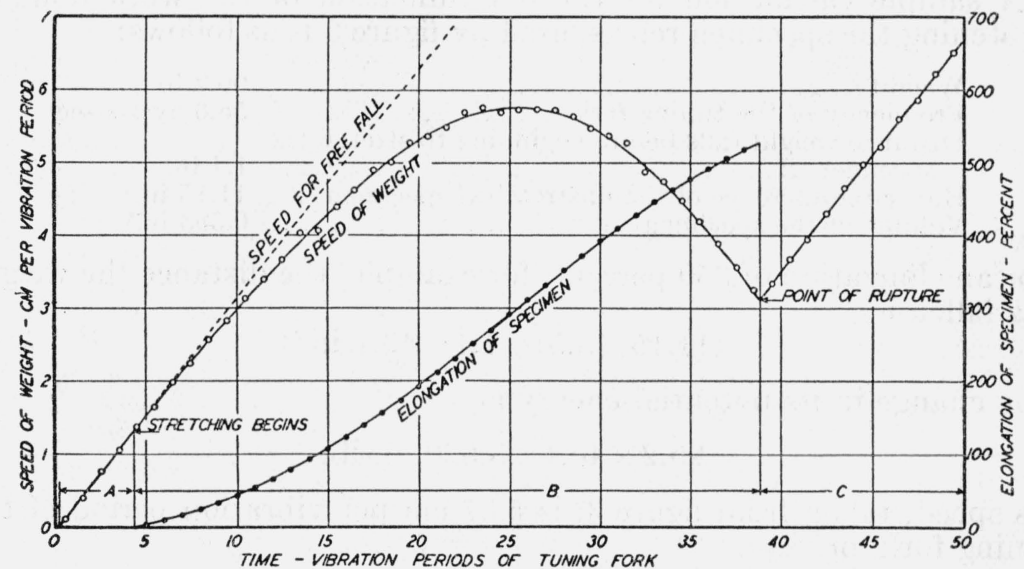

FiguRE 3.-Speed-time and elongation-time curves for a specimen of channel black compound stretched by the falling weight.

The positions of the spark holes in the tape are measured by means of a low-power microscope and a millimeter scale. The distance between any two consecutive holes, after the starting point, is numerically equal to the average speed of the weight during the corresponding time interval and is equal, to a first-order approximation, to the instantaneous speed at a time midway between the beginning and end of the interval. Figure 3 shows a typical speed-time graph plotted by this method. Region $A$ corresponds to the free fall of the weight before it begins to stretch the specimen. The distance of free fall was found by direct measurement before the weight was released, and in this case was 1.1 inches $(2.8 \mathrm{~cm})$. Region $B$ represents the fall of the weight under the action of the upward pull of the specimen. Region $C$ represents the free fall of the weight following the rupture of the specimen.

The tensile properties of the specimen may be determined in either of two ways: (1) The tension in the specimen may be determined at any point during its stretch from the speed-time curve; or (2) the work done by the weight on the specimen may be determined and 
plotted as a function of its elongation, and the tensile properties may be determined from the resulting graph. In the first method the tension, especially for low elongations, must be obtained from the difference of two relatively large quantities. Consequently, this method was abandoned in favor of the less direct method, that of considering the work done by the weight on the specimen.

Since data obtained by allowing the weight to fall without a specimen in place show that frictional forces due to the tape are negligible, the work done on the specimen is equal to the difference between the change in potential energy of the weight due to its change in position and the kinetic energy due to its speed. The curves in figure 3 are needed only to determine the speed of the weight as a function of the elongation of the specimen and to determine the ultimate elongation of the specimen.

\section{(b) SAMPLE CALCULATION}

A sample calculation for the determination of the work done in stretching the specimen represented by figure 3 is as follows:

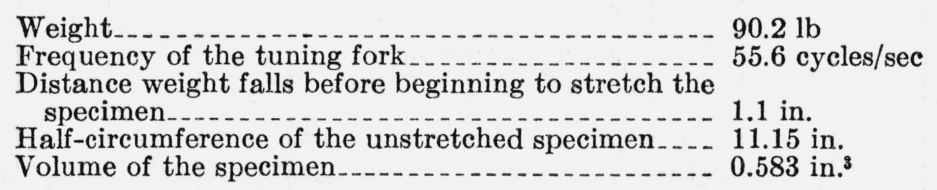

For an elongation of 350 percent, for example, the distance the weight has fallen is

$$
(11.15 \times 3.5)+1.1=40.1 \mathrm{in} .
$$

The change in its potential energy is

$$
90.2 \times 40.1=3,620 \text { in. }-\mathrm{lb} \text {. }
$$

Its speed, taken from figure 3 , is $5.67 \mathrm{~cm}$ per vibration period of the tuning fork, or

$$
\frac{5.67 \times 55.6}{2.54}=124 \mathrm{in} . / \mathrm{sec} \text {. }
$$

The gravitational constant is $980 / 2.54=386 \mathrm{in} . / \mathrm{sec}^{2}$.

The kinetic energy of the weight is given by

$$
\frac{90.2 \times(124)^{2}}{2 \times 386}=1,800 \text { in.-lb. }
$$

The work done per cubic inch of the specimen in stretching 350 percent is

$$
\frac{3,620-1,800}{0.583}=3,120 \text { in.-lb./in }{ }^{3} \text {. }
$$

Similar calculations may be carried out for as many elongations as may be desired. Figure 4 shows the work done per unit volume of the sample plotted as a function of the elongation. Since for any given elongation the stress is equal to the ratio of the change in work done per unit volume to the corresponding change in strain, the slope at any point of the work curve, figure 4 , is equal to the stress at the corresponding strain. Therefore the stress-strain curve for the speci- 
men can easily be plotted either from an analytical treatment of the work data or by graphical means. Both methods were employed in the present investigation.

\section{(c) PRECISION}

The precision of the measurements for high rates of stretch is as good as can be obtained by the usual testing methods. Tables 2 and 3 show the work of extension at various elongations of pure-gum and

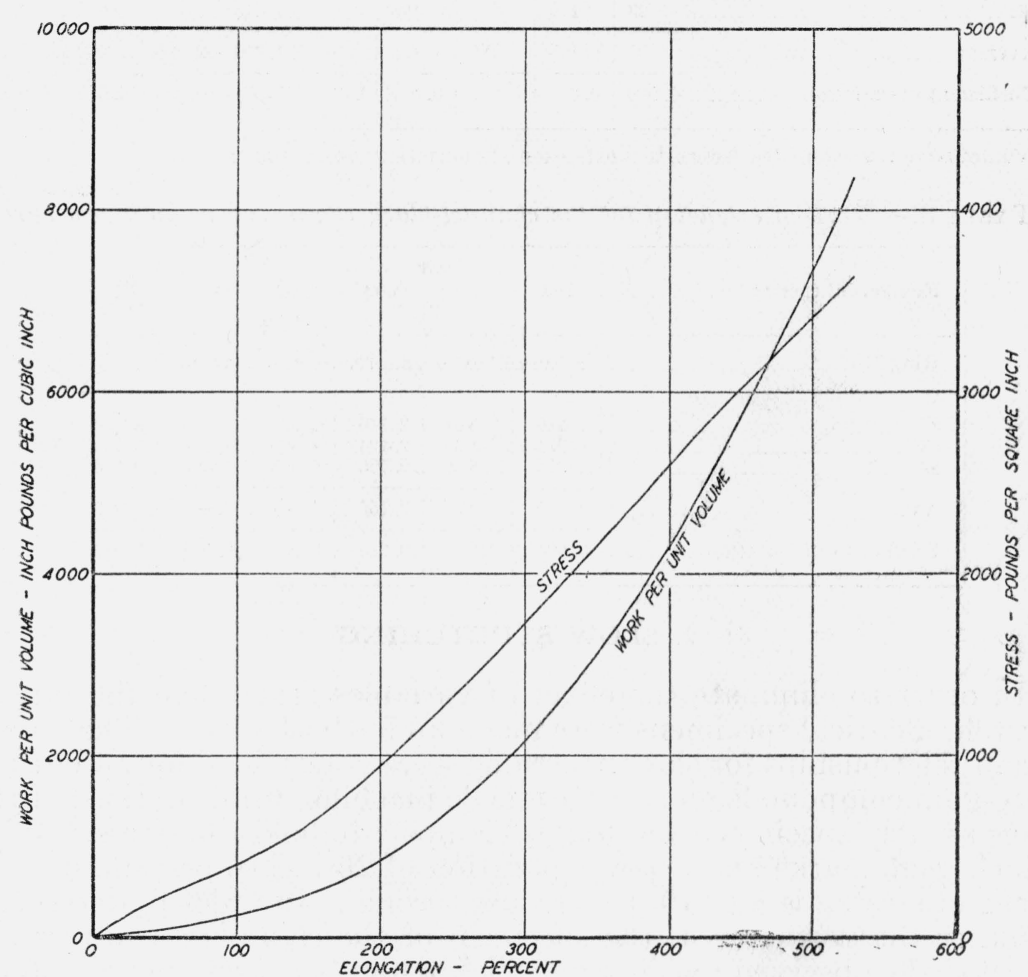

FIGURE 4.-Work-elongation curve and the stress-strain curve obtained from it.

The work-elongation curve is derived from figure 3.

channel-black compounds at optimum cure and are illustrative of the general precision obtained. The coefficient of variation used in these tables is defined as the ratio of the standard deviation to the mean, the standard deviation being the square root of the mean of the squares of the deviations of the individual observations from their mean. The coefficients of variation observed at rupture are in good agreement with the value 0.05 stated by Holt and McPherson ${ }^{16}$ to be that commonly obtained by the usual testing methods.

\footnotetext{
${ }^{16}$ W. L. Holt and A. T. McPherson, Toggle clamp for rubber tensile specimens, J. Research NBS 22, 543 (1939) RP1204.
} 
TABLE 2.-Work of extension for the pure-gum compound at optimum cure

\begin{tabular}{|c|c|c|c|c|c|c|c|c|c|}
\hline Elongation (percent) & 50 & 150 & 250 & 350 & 450 & 550 & 650 & 750 & $\begin{array}{l}\text { Rup- } \\
\text { ture }\end{array}$ \\
\hline Ring No. & \multicolumn{9}{|c|}{ Work of extension, inch-pounds per cubic inch } \\
\hline 257 & 26 & 115 & 274 & 491 & 837 & 1,390 & 2,265 & 4,000 & $\begin{array}{l}5,340 \\
5,510\end{array}$ \\
\hline $261--$ & $\begin{array}{l}25 \\
22\end{array}$ & 124 & 287 & 498 & $\begin{array}{l}840 \\
808\end{array}$ & $\begin{array}{l}1,380 \\
1,355\end{array}$ & $\begin{array}{l}2,350 \\
2\end{array} 270$ & $\begin{array}{l}4,130 \\
4,030\end{array}$ & $\begin{array}{l}5,070 \\
5,900\end{array}$ \\
\hline $\begin{array}{l}263^{a} \\
264^{-}\end{array}$ & 23 & 120 & 280 & 498 & 828 & 1,315 & 2,260 & 4,080 & $\begin{array}{l}5,520 \\
5,920\end{array}$ \\
\hline Average.. & 24 & 118 & 280 & 498 & 828 & 1,360 & 2,285 & 4,060 & 5,543 \\
\hline Coefficient of variation & 0.066 & 0.034 & 0.017 & 0.011 & 0.015 & 0.021 & 0.016 & 0.012 & 0.054 \\
\hline
\end{tabular}

- Values were not calculated for work of extension at elongations below rupture.

TABLE 3.-Work of extension for the channel-black compound at optimum cure

\begin{tabular}{|c|c|c|c|c|c|c|}
\hline Elongation (percent) & 100 & 200 & 300 & 400 & 500 & $\begin{array}{l}\text { Rup- } \\
\text { ture }\end{array}$ \\
\hline Ring No........... & \multicolumn{6}{|c|}{ Work of extension, inch-pounds per cubic inch } \\
\hline 88 89 89 & $\begin{array}{l}216 \\
214 \\
215\end{array}$ & $\begin{array}{l}840 \\
859 \\
833\end{array}$ & $\begin{array}{l}2,140 \\
2,194 \\
2,130\end{array}$ & $\begin{array}{l}4,290 \\
4,360 \\
4,270\end{array}$ & $\begin{array}{l}7,310 \\
7,456 \\
7,360\end{array}$ & $\begin{array}{l}8,330 \\
9,235 \\
9,170\end{array}$ \\
\hline A verage....... & 215 & 844 & 2,155 & 4,307 & 7,375 & 8,910 \\
\hline Coefficient of variation..... & 0.004 & 0.013 & 0.013 & 0.009 & 0.008 & 0.046 \\
\hline
\end{tabular}

\section{SLOW STRETCHING}

In order to eliminate the effect of variables other than the rate of stretch, identical specimens were made up for both rates. The stressstrain relationships for slow stretching were determined for all but the pure-gum compounds on a Scott tensile machine, using sections of the rings as strip specimens and toggle clamps ${ }^{17}$ to hold the strips. With 2-inch gage marks and a jaw separation of 20 inches per minute, the speed of stretch is 8 to 10 percent per second. In order to determine whether the geometry of the specimen or the clamping arrangement affected the observed tensile properties, a number of rings of a carbonblack compound were stretched at about the same rate, 8 to 10 percent per second, over the lubricated spools used for rapid stretching. The resulting stress-strain curves, including the average ultimate elongations and tensile strengths were not appreciably different from those obtained with strip specimens of the same compound. Since strips from the pure-gum rings showed a decided tendency to break in or near the clamps, all the data for this compound were obtained by stretching complete rings over the lubricated spools.

\footnotetext{
${ }^{17} \mathrm{~W} . \mathrm{L}$. Holt and A. T. McPherson, Toggle clamp for rubber tensile specimens, J. Research NBS 22,543 (1939) RP1204.
} 


\section{EXPERIMENTAL RESULTS}

\section{STRESS-STRAIN RELATIONSHIPS}

Stress-strain curves for the optimum cure of each compound are shown in figure 5. In each case the solid line refers to rapid stretching and the broken line refers to slow stretching. The data corresponding to the points shown are tabulated in table 4 . It will be noted that

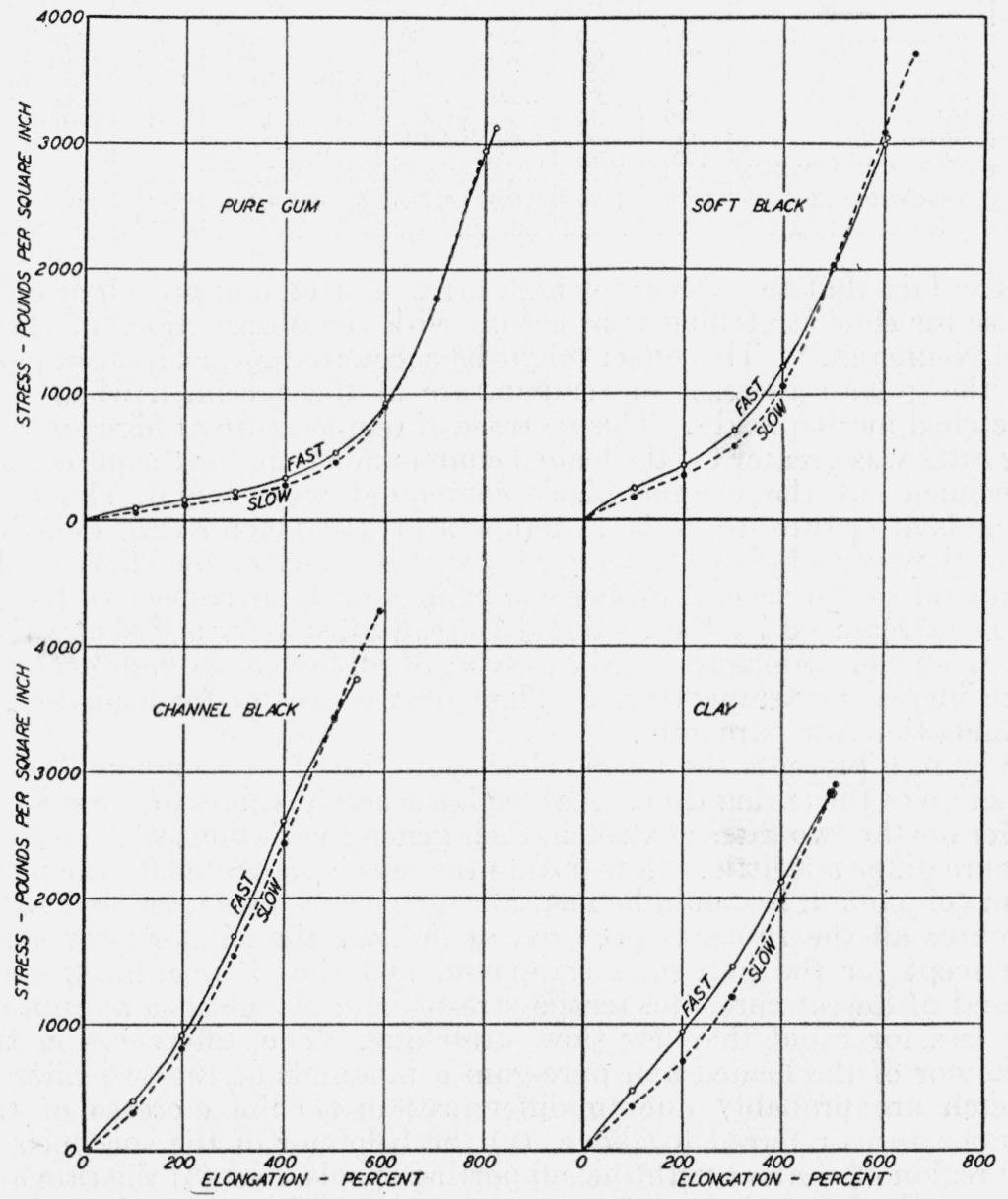

FIGURE 5.-Comparative stress-strain curves for two rates of stretch.

The curves are based on the optimum cures of the compounds described in table 1.

for elongations up to about 500 or 600 percent the stress at a given elongation is greater for rapid stretching. For the pure-gum compound the difference in the stresses for the two rates of stretch reaches a maximum of 75 pounds per square inch at 500-percent elongation. At elongations greater than 600 percent the difference is negligible. For the loaded compounds the difference is somewhat greater but vanishes at about 500-percent elongation and reverses its sign at higher elongations. 
TABLE 4.-Comparison of stresses of rubber compounds at optimum cure for the two rates of stretch

\begin{tabular}{|c|c|c|c|c|c|c|c|c|}
\hline Compound............ & \multicolumn{2}{|c|}{ Pure gum } & \multicolumn{2}{|c|}{ Soft black } & \multicolumn{2}{|c|}{ Channel black } & \multicolumn{2}{|c|}{ Clay } \\
\hline Rate of stretch & Fast & Slow & Fast & Slow & Fast & Slow & Fast & Slow \\
\hline Elongation & \multicolumn{8}{|c|}{ Stress, pounds per square inch } \\
\hline $\begin{array}{l}\quad \text { Percent } \\
100 \\
300 \\
400 \\
600\end{array}$ & $\begin{array}{r}92 \\
161 \\
220 \\
329 \\
530 \\
912 \\
1,770 \\
\end{array}$ & $\begin{array}{r}56 \\
107 \\
173 \\
270 \\
455 \\
895 \\
1,760\end{array}$ & $\begin{array}{r}250 \\
435 \\
705 \\
1,225 \\
2,010 \\
2,990 \\
\end{array}$ & $\begin{array}{r}180 \\
355 \\
580 \\
1,070 \\
2,025 \\
3,085\end{array}$ & $\begin{array}{r}390 \\
910 \\
1,700 \\
2,610 \\
3,430 \\
\end{array}$ & $\begin{array}{r}295 \\
810 \\
1,540 \\
2,430 \\
3,415 \\
\\
\end{array}$ & $\begin{array}{r}470 \\
940 \\
1,460 \\
2,130 \\
2,840 \\
\end{array}$ & $\begin{array}{r}345 \\
705 \\
1,215 \\
1,980 \\
2,840 \\
\cdots \\
\cdots\end{array}$ \\
\hline Tensile strength... & 3,120 & 2,850 & 3,040 & 3,705 & 3,740 & 4,280 & 2,840 & 2,900 \\
\hline
\end{tabular}

The fact that the curves for high rates of stretch approach or cross those for slow stretching is in accord with the observations of Hauk and Neumann. ${ }^{18}$ This effect might be accounted for, at least in part, by the greater increase of temperature of the specimen when it is stretched more quickly. This increase of temperature at high stretching rates was greater for the loaded compounds than for the pure-gum. Specimens of the channel-black compound were found, about 15 seconds after rupture, to be at temperatures as much as $25^{\circ} \mathrm{C}$ higher than they were before stretching began. A study of the effect of the temperatures of several rubber compounds on their respective tensile stresses, reported by the National Bureau of Standards, ${ }^{19}$ shows that for given elongations the tensile stresses of rubber compounds decrease with increasing temperatures. This effect is greater for loaded compounds than for pure gum.

Figure 6 presents the tensile characteristics of the compounds as a function of the curing time. Although the actual values of the stresses differ for the two rates of stretch, their general variations with changes in cure differ but little. In regard to the tensile strengths for the puregum compound, it should be mentioned that for cures greater than 30 minutes all the ruptures occurred at or near the supporting spools.

Except for the pure-gum compound and the channel-black compound of lowest cure, the tensile stresses and elongations at rupture are less for rapid than for slow stretching. The differences in the behavior of the loaded and pure-gum compounds at the two rates of stretch are probably due to differences in (1) the increase of the temperatures referred to above, (2) the behavior of the specimen at the region of contact with the supporting spools, and (3) the rate and type of fibering ${ }^{20}$ of the different compounds. No attempt is made to explain the exact causes of the observed differences.

\footnotetext{
$18 \mathrm{~V}$. Hauk and W. Neumann, Isothermal and adiabatic stress-strain curves of vulcanized rubber, Monatsh. 72, 22 (1938); Translated in Rubber Chem. Tech. 12, 64 (1939).

io R. F. Tener, S. S. Kingsbury, and W. L. Holt, Tensile properties of soft rubber compounds at temperatures ranging from $-70^{\circ}$ to $+147^{\circ}$ C., Techn. Pap. BS 22, 367 (1928) T364.

20 Fibering or "crystallization" of rubber compounds is a well-known phenomenon of phase change which occurs in rubber when it is stretched. This phase change is evidenced by changes in X-ray diffraction patterns, specific volumes, and by specific heats. Fibering is influenced by differences in compounds, amount and rate of stretch of the specimens, and by temperature. In effect, the stress-strain curve for low elongations represents the tensile properties of an amorphous substance, whereas the same curve for higher elongations may represent the tensile properties of a type of crystalline substance. Thus, it is difficult to predict the exact causes of the observed differences in tensile strengths for the various compounds when they are stretched at different rates.
} 


\section{WORK OF EXTENSION}

Table 5 shows the work of extension of the rubber compounds at optimum cure tabulated as a function of elongation. For the compounds investigated the ratio of the work of extension for slow stretch-

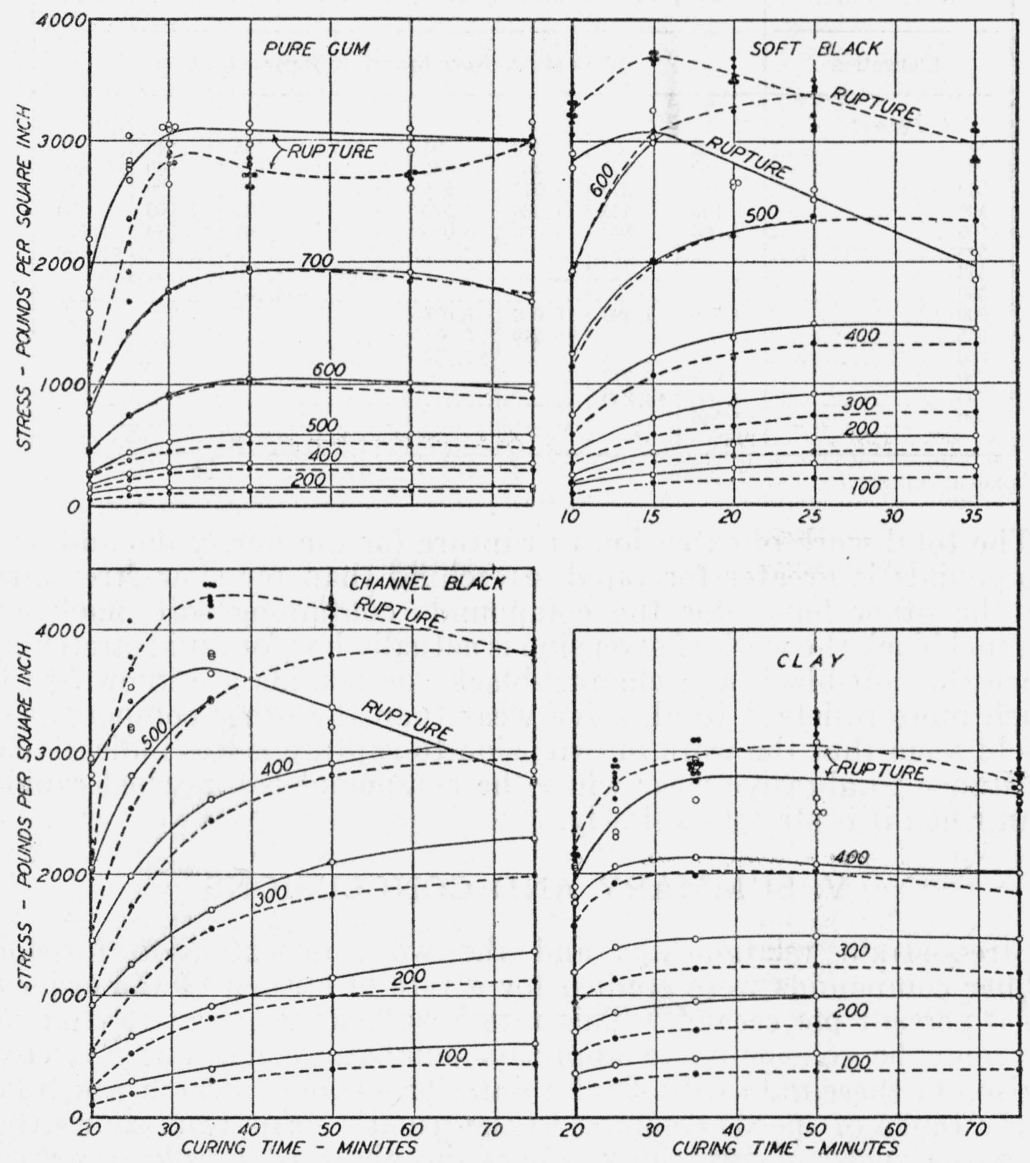

FIgURE 6.--Stresses and tensile strengths for the two rates of stretch as a function of the time of cure.

The solid-line and broken-line curves refer respectively to rapid and slow stretching. The numbers on the curves indicate the percent elongation. The compounds are those described in table 1.

ing to that for rapid stretching, at equal elongations, ranges from about 0.6 at 100 -percent elongation to about 0.9 in the neighborhood of rupture. The relative constancy of this ratio at each elongation makes it evident that the work of extension for a given elongation obtained by rapid stretching gives no better indication of the nature of a compound than can be obtained by slow stretching. 
TABLE 5.-Comparison of work of extension of rubber compounds at optimum cure for the two rates of stretch

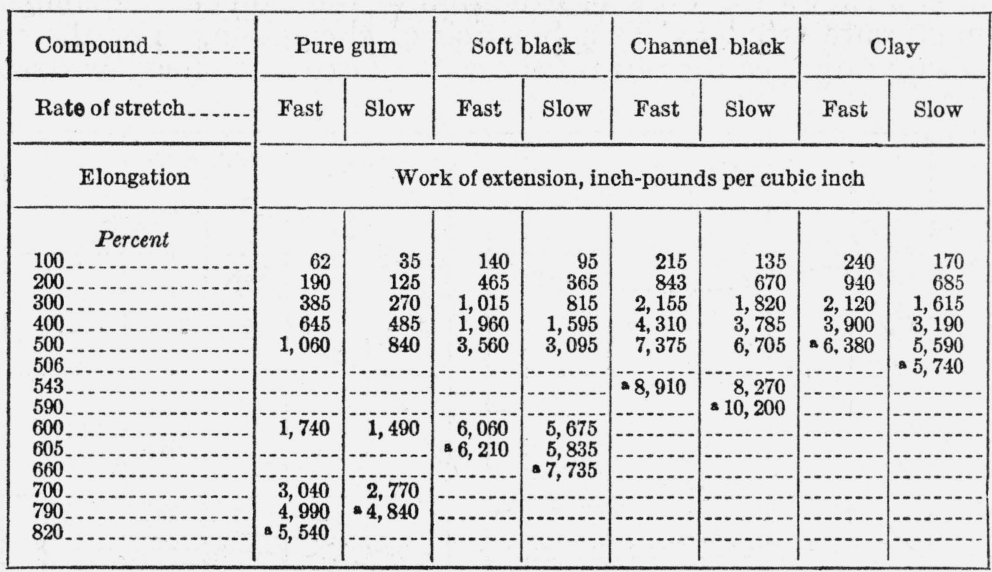

-Values at rupture.

The total work of extension to rupture for the pure-gum and clay compounds is greater for rapid stretching than for slow stretching. On the other hand, for the compounds containing soft black and channel black the work of extension is actually less for rapid stretching. Since the soft-black and channel-black compounds are known to be much more resistant to abrasive wear than the other compounds, it would seem that the work of extension to rupture is less indicative of resistance to abrasive wear when the compound is stretched rapidly than when it is stretched slowly.

\section{SUMMARY AND CONCLUSIONS}

Stress-strain relationships and the work of extension for four rubber compounds were studied for a rate of stretch of the order of 1,000 percent per second. This rate is sufficiently great so that the test may be considered to approach adiabatic conditions. A comparison of these data with similar data for a rate of stretch which lies in the range of speeds common to the usual routine tests shows that increased speed of stretching affects the observed tensile properties as follows: (1) The stresses are increased at elongations up to about 500 percent for the loaded compounds and up to 600 percent for the pure-gum compound, the maximum increases ranging from 75 pounds per square inch for the pure-gum compound to 245 pounds per square inch for the clay compound; (2) the stresses in the carbon-black compounds are decreased slightly at elongations near rupture; (3) the work of extension to rupture is increased for the pure-gum and clay compounds and decreased for the carbon-black compounds; and (4) the work of extension for a given elongation is increased for all the compounds. The stresses and the work of extension at the higher speed reveal no information indicative of resistance to abrasive wear that cannot be gained from similar studies of data obtained in stretching the specimen slowly.

Washington, September 13, 1939. 